NBER WORKING PAPER SERIES

\title{
THE EFFECT OF HOSPITAL NURSE STAFFING ON PATIENT HEALTH OUTCOMES: EVIDENCE FROM CALIFORNIA'S MINIMUM STAFFING REGULATION
}

\author{
Andrew Cook \\ Martin Gaynor \\ Melvin Stephens, Jr. \\ Lowell Taylor \\ Working Paper 16077 \\ http://www.nber.org/papers/w16077 \\ NATIONAL BUREAU OF ECONOMIC RESEARCH \\ 1050 Massachusetts Avenue \\ Cambridge, MA 02138 \\ June 2010
}

We wish to thank the California Office of Statewide Health Planning and Development for providing the data used in this study. Melissa Taylor and participants in a session at the 2009 American Economic Association annual meeting provided valuable comments and suggestions. All responsibility for the content of this paper rests with the authors alone. The views expressed herein are those of the authors and do not necessarily reflect the views of the National Bureau of Economic Research.

NBER working papers are circulated for discussion and comment purposes. They have not been peerreviewed or been subject to the review by the NBER Board of Directors that accompanies official NBER publications.

(C) 2010 by Andrew Cook, Martin Gaynor, Melvin Stephens, Jr., and Lowell Taylor. All rights reserved. Short sections of text, not to exceed two paragraphs, may be quoted without explicit permission provided that full credit, including $(\mathrm{C}$ notice, is given to the source. 
The Effect of Hospital Nurse Staffing on Patient Health Outcomes: Evidence from California's Minimum Staffing Regulation

Andrew Cook, Martin Gaynor, Melvin Stephens, Jr., and Lowell Taylor

NBER Working Paper No. 16077

June 2010

JEL No. I10,I18,J08

\begin{abstract}
Hospitals are currently under pressure to control the cost of medical care, while at the same time improving patient health outcomes. These twin concerns are at play in an important and contentious decision facing hospitals-choosing appropriate nurse staffing levels. Intuitively, one would expect nurse staffing ratios to be positively associated with patient outcomes. If so, this should be a key consideration in determining nurse staffing levels. A number of recent studies have examined this issue, however, there is concern about whether a causal relationship has been established. In this paper we exploit an arguably exogenous shock to nurse staffing levels. We look at the impact of California Assembly Bill 394, which mandated minimum levels of patients per nurse in the hospital setting. When the law was passed, some hospitals already had acceptable staffing levels, while others had nurse staffing ratios that did not meet mandated standards. Thus changes in hospital-level staffing ratios from the preto post-mandate periods are driven in part by the legislation. We find persuasive evidence that AB394 did have the intended effect of decreasing patient/nurse ratios in hospitals that previously did not meet mandated standards. However, our analysis suggests that patient outcomes did not disproportionately improve in these same hospitals. That is, we find no evidence of a causal impact of the law on patient safety.
\end{abstract}

Andrew Cook

Resolution Economics LLC

9777 Wilshire Boulevard Suite 600

Beverly Hills, CA 90212

acook@resecon.com

Martin Gaynor

Heinz College

Carnegie Mellon University

4800 Forbes Avenue, Room 241

Pittsburgh, PA 15213-3890

and NBER

mgaynor@cmu.edu
Melvin Stephens, Jr.

University of Michigan

Department of Economics

611 Tappan St.

Ann Arbor, MI 48109-1220

and NBER

mstep@umich.edu

Lowell Taylor

The Heinz School

Carnegie Mellon University

5000 Forbes Avenue

Pittsburgh, PA 15213-3890

1t20@andrew.cmu.edu 


\section{Introduction}

Hospitals are currently under pressure to control the cost of medical care, while at the same time improving patient health outcomes, especially though the reduction of medical error (Kohn, Corrigan, and Donaldson, 1999). These twin concerns are at play in an important and contentious decision facing hospitals—choosing appropriate nurse staffing levels.

Intuitively, one would expect that relatively high nurse staffing ratios to be associated with improved patient outcomes, and if this intuition is correct, these patient benefits should be a key consideration in the determination of nurse staffing levels. Ideally, hospitals' decisions about nurse staffing should be guided by clear empirical evidence on this matter, and indeed a number of recent studies have examined this issue. The best known of these papers are the seminal contributions of Aiken, et al. (2002) and Needleman, et al. (2002). Using data from 168 hospitals in Pennsylvania covering a 20 month span Aiken, et al. (2002) demonstrate that cross-sectional variation in nurse staffing levels is negatively correlated with patient mortality, measured as risk-adjusted 30-day mortality and failure to rescue rates. ${ }^{1}$ The Needleman, et al. (2002) analysis of administrative data from 799 hospitals in 11 states over a one-year span also found higher levels of nurse staffing to be associated with lower failure to rescue rates, and they also reported improved patient outcomes along a variety of other specific dimensions, e.g., rates of urinary tract infection, upper gastrointestinal bleeding, pneumonia, and shock or

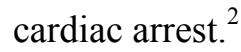

The regression analyses of Aiken, et al. (2002) and Needleman, et al. (2002), provide important evidence about cross-sectional correlations, but concerns remain about causal relationships. In this regard, there are two important potential problems.

The first issue is a particular form of omitted variable bias. There exists considerable variation across hospitals in the level of resources devoted to patient care. This variation exists in nurse staffing practices, of course, but also along many other dimensions - the quantity and quality of medical

\footnotetext{
${ }^{1}$ Failure to rescue indicates patients who have died after developing a complication while in the hospital—patients who, under normal circumstances of care, might have been "rescued" from the complication.

${ }^{2}$ See also Lang, et al., (2004) for a review and discussion of the literature.
} 
equipment, the adoption of educational efforts to keep medical staff current on best practices, the efficacy of management practices, etc. (e.g., McClellan and Staiger, 2000; Bloom et al., 2009; Propper and Van Reenen, 2010). In cross-sectional regression analyses, attempts are made to control for such factors, but researchers typically have an extremely limited set of covariates to work with. If, as one might suspect, hospitals that have relatively high nurse staffing levels also have above-average levels of other (unobserved) factors that affect patient care, cross-sectional regression analysis will tend to overstate the impact of a high nurse/patient ratio on patient health outcomes.

The second problem has to do with endogenous sorting. In general we would expect that medical providers will devote relatively high resources to patients for whom these resources are likely to have the highest impact — often to those patients who are at greatest risk of adverse outcomes. For example, we expect high mortality rates on medical units with high nurse/patient ratios. Again, a researcher can attempt to control for the severity of patients' medical conditions, but this is difficult to do with available data. In this case, researchers will tend to underestimate the beneficial impact of high nurse-to-patient ratios on patient outcomes.

Similar concerns pertain to evaluations based on hospital-level panel data (e.g., Sochalski, et al., 2008). Thus, hospitals that experience improved nurse staffing levels might well be increasing resources along other (unobserved) dimensions. Conversely, hospitals that increase their nurse staffing levels might well be doing so in response to increases in general acuity levels of their patients.

A sensible response to these concerns is for the researcher to search for exogenous shifts to nurse staffing, and then use that variation to explore the impact on patient outcomes. Although truly exogenous variation (e.g., randomized assignment) is unavailable for this purpose, there are some attempts to find “natural experiments” for generating plausibly exogenous changes in nurse-per-patient ratios. A good example of this approach is the innovative work of Evans and Kim (2006). Their identification strategy is to exploit natural variation that occurs in hospital admissions, which in turn create variation in patient loads. Using this approach, Evans and Kim find that patients admitted when the patient loads are high 
tend to have higher mortality, but effects are estimated to be quite small and are not statistically significant in several of their specifications. As the authors acknowledge, interpretation is difficult because they "have no independent data about how hospitals deal with a sudden influx of patients." Thus, if hospitals respond by offering overtime shifts to nurses, in fact the nurse-to-patient ratios might not be changing much when there is a surge in hospital admissions. This could lead the authors to underestimate the impact of patient loads on patient outcomes. ${ }^{3}$

Our paper contributes by providing a new analysis that exploits an arguably exogenous shock to nurse staffing levels for the purpose of studying the relationship between nurse staffing levels and patient outcomes. Specifically, we look at the impact of California Assembly Bill 394, which mandated maximum levels of patients per nurse in the hospital setting. When the law was passed, some hospitals already had acceptable staffing levels, while others had nurse staffing ratios that did not meet mandated standards. Thus changes in hospital-level staffing ratios from the pre- to post-mandate periods are driven in part by the legislation. Our goal is to look at the impact on key patient health outcomes.

\section{California Assembly Bill 394}

In 1999 the California legislature passed AB394, which started a process whereby maximum patient-to-nurse ratios were set for the State's hospitals. After the Bill initially passed, the California Department of Health Services (DHS) spent two years holding hearings in which stakeholders were invited to make recommendations regarding the appropriate nurse staffing levels. In response to the invitation, the top two nurse unions, the California Nurses Association and the Service Employees International Union, along with the California Healthcare Association (an organization representing many of California's hospitals), proposed ratios that they considered appropriate (Spetz, 2004). In addition, the DHS presented their own draft nurse staffing ratios (in January of 2002). In mid-2002, the DHS

\footnotetext{
${ }^{3}$ See also Dobkin (2003) and Bartel, et al. (2009) for studies which employ similar identification strategies.
} 
announced the final standards, which were initially to be implemented in July 2003. This proposed mandate was finally implemented on January $1,2004{ }^{4}$

The hope, of course, was that increased levels of nurse staffing would be beneficial to patient outcomes. But from the outset nursing unions noted two major concerns about the legislation that could undermine that goal. The first issue was enforcement. Under the current guidelines, the DHS is only permitted to require an "action plan" created by the hospital, which would address any violations that occur in the hospital, and how these deficiencies will be rectified, but assesses no fine or set period in which the plan must be implemented (Spetz, 2004). Below we present evidence that in fact patient-tonurse ratios did decline in hospitals that did not meet standards prior to the legislation implementation. ${ }^{5}$ The second concern was that in the process of complying with the patient-to-nurse ratio requirements, hospitals might reduce employment of non-nursing personnel, and ask nurses to perform tasks previously undertaken by these employees (Coffman, Seago, and Spetz, 2002; Clarke, 2003; and Spetz, 2004). Such actions would presumably reduce the effectiveness of the legislation in promoting improved patient outcomes. While we cannot directly analyze this issue directly, we do of course look at the key issuethe impact on patient outcomes. First we describe our data.

\footnotetext{
${ }^{4}$ The ratios are implemented for the following hospital units in general acute care, acute psychiatric, and specialty hospitals: critical care unit, burn unit, labor and delivery unit, post-anesthesia service area, emergency department, operating room, pediatric unit, step-down/intermediate care unit, specialty care unit, telemetry unit, general medical care unit, sub-acute care unit, and transitional inpatient care unit.

${ }^{5}$ See also Spetz, et al. (2009) and Matsudaira (2009), who likewise show that nurse staffing increased as a consequence of the regulations.
} 


\section{Data and Descriptives}

\section{A. Data Sources and Key Variables}

This study utilizes data from California's Office of Statewide Health Planning and Development (OSHPD) financial reports and patient discharge database for nonfederal hospitals for the years 2000 through 2006. The annual hospital financial reports contain information on financial status, service mix, staffing levels, patient loads, and cost allocations. The administrative patient discharge data provide information on each patient discharged, including patient characteristics, the patient's medical condition, the condition severity, and any procedures performed on the patient before discharge. As we have mentioned, AB394 was implemented in January 2004, but was under discussion for two years prior to implementation. Thus, we treat the years 2000-2002 as the "pre-implementation" period. We use 20052006 as the "post-implementation" period, which allows for a one-year period for hospital adjustment to the regulation.

The use of administrative discharge data is quite common in the study of patient outcomes. These publicly available data include all non-federal California hospitals, and they include all the necessary variables (age, sex, DRGs, MDCs, etc.) to obtain risk-adjusted rates for the patient safety indicators that we will be analyzing in this study. ${ }^{6}$ These data do, however, likely have measurement error (due to self-report information), and we should note that the staffing hours do not differentiate between patient-care hours and those hours spent employed in such non-patient work as administration, teaching, attending educational functions, etc. (a point noted also by Dobkin, 2003).

Our focus is general medical/surgical hospital units, which represent roughly half of all inpatient discharges in non-federal California hospitals. General medical/surgical units treat patients with medical and/or surgical conditions who do not require an intensive care setting. We concentrate on these units as

\footnotetext{
${ }^{6}$ We use Agency for Healthcare Research and Quality (AHRQ) software to create the patient safety indicators, as discussed below. See http://www.qualityindicators.ahrq.gov/psi_overview.htm.
} 
the OSHPD data only provide the necessary nurse labor information for such units. ${ }^{7}$ One difficulty concerning OSHPD patient discharge data is that there are no identifiers for the unit where a patient was treated. To create such units from the available OSHPD data, we use a methodology created by the Institute for Health and Socio-Economic Policy (Institute for Health and Socio-Economic Policy, 2001) whereby an RN expert panel is used to assign DRGs (diagnosis related groups) to one of seven hospitallevel units (intensive care unit, burn care, definitive observation, medical/surgical, pediatrics, psychiatrics, and obstetrics). Appendix A provides a discussion.

The first key variable is an approximation useful for examining the nurse staffing level. The OSHPD Annual Hospital Financial Data provide information sufficient for this purpose. In particular, OSHPD requests that hospitals report unit-level productive hours worked for RNs, LVNs, and aides/orderlies. Productive hours worked are total hours worked by each staffing level, excluding vacation, leave, etc. OSHPD also provides unit-level information on patient census days (total days patients spend in the unit). Thus, to obtain ratios, we first must calculate productive hours per patient day (PHPD), as the ratio of "productive hours worked" to "patient census days." 8 For the purpose of this study, productive hours worked include hours for both registered nurses (RNs) and licensed vocational nurses (LVNs). Then, to obtain an approximation of nurse-to-patient staffing ratios, we divide PHPD by 24. ${ }^{9}$ For the analysis below we use the reciprocal of this measure — the patient-to-nurse ratio - as the key nurse staffing variable. ${ }^{10}$

\footnotetext{
${ }^{7}$ We considered analyzing two additional types of hospital units, critical care and step-down/telemetry. However, critical care units already had strict patient-to-nurse requirements and were thus unaffected by this legislation. We did not have sufficient observations to evaluate patient health outcomes in step-down/telemetry units.

${ }^{8}$ We remove hospital units with missing information on productive hours worked and/or patient census days. We also removed 5 hospital units that had implausible PHPD outlier values, as depicted on page II-7 in Kravitz and Sauve (2002). (This happened when a hospital unit had a PHPD value above 24, as it is not possible to work more than 24 hours per day.)

${ }^{9}$ This calculation implicitly assumes that the average patient day is 24 hours - an assumption that is generally not correct. In this respect our patient-to-nurse ratio can be thought of as an upper bound.

${ }^{10}$ Analyses based on the nurse-to-patient ratio values yield qualitatively similar results.
} 
Our study uses two patient safety indicators (PSIs) created by the Agency for Healthcare Research and Quality (AHRQ) to measure adverse health outcomes in the patient hospital population, both of which are potentially affected by nurse staffing — estimated rates of "failure to rescue" and "decubitus ulcers." 11

Failure to rescue indicates patients who have died after developing a complication while in the hospital - patients who, under normal circumstances of care, might have been "rescued" from the complication. There are six complications associated with this indicator: pneumonia, deep vein thrombosis/pulmonary embolism, sepsis, acute renal failure, shock/cardiac arrest, and gastrointestinal hemorrhage/acute ulcer. Medical personnel in high-quality hospitals are expected to identify these complications promptly and treat them aggressively. AHRQ has designated this outcome as potentially sensitive to changes in nurse staffing (Agency for Healthcare Research and Quality, 2003). As we discuss above, in both Aiken, et al. (2002) and Needleman, et al. (2002) high patient-to-nurse ratios are associated with relatively higher rates of failure to rescue.

Decubitus ulcers are bedsores which develop when there is a failure to frequently move an immobile patient. Knowledge of decubitus ulcer formation and prevention is a topic that is carefully covered in nursing school curriculum (Rosdahl and Kowalski, 2007). Several cross-sectional studies indicate that high patient-to-nurse ratios are associated with relatively higher rates of decubitus ulcers. Examples include Lichtig, et al. (1999), Unruh (2003), Stone, et al. (2007), and Spetz, et al. (2009). ${ }^{12}$

\section{B. Descriptive Statistics}

Tables 1 through 3 show mean levels for key variables - the patient-to-nurse ratio (PNR), the failure to rescue rate (FTR) and rate of decubitus ulcers (DU) — for each year in the study period. In

\footnotetext{
${ }^{11}$ See Appendix B for more details.

${ }^{12}$ However, Needleman, et al. (2001) and Donaldson (2005) find no evidence of this relationship, and Cho, et al. (2003) actually discover a somewhat higher probability of bedsores with the rise in nurse staffing. Below we discuss difficulties in interpreting the relationship between the patient-to-nurse ratio and the rate of decubitus ulcers.
} 
presenting these means, we categorize units by the units' average PNR as calculated over the 2000-2002 period. AB394, as implemented in 2004, requires the PNR to be 5 or lower on medical/surgical units. We divide our sample into four groups: two groups of hospitals not compliant with the regulation (hospitals with PNR $>6$, and $6 \geq$ PNR $>5$ ) and two groups of hospitals with PNRs that conform to the regulation (those with $5 \geq \mathrm{PNR}>4$, and those for which $4 \geq \mathrm{PNR}$ ). Using these four groups allow us to distinguish between hospitals that are closer to the boundary of the regulation versus those that are well above or well below the required ratio.

Consider Table 1. The first three columns show that there was considerable variation in observed PNRs among California's non-federal hospitals. For example, 53 hospitals averaged PNR $>6$ over the 2000-2002 period, and the averages in these units were 6.64, 7.17, and 7.36, respectively, in 2000, 2001, and 2002. At the opposite extreme, there were 51 hospitals with PNR averages of 4 or less, with average ratios of 3.23 in 2000 and 3.55 in both 2001 and 2002.

Table 1 thus suggests that many hospitals were using patient loads that substantially exceeded the mandate established by AB394. Statistics presented in the Table also show that these same hospitals substantially reduced patient/nurse ratios post-regulation - likely in response to the regulation. In particular, those hospitals that initially had the highest patient/nurse ratios in 2000-2002 experienced sharply declining ratios by 2005-2006, while in contrast, those hospitals that initially had the lowest patient/nurse ratios in 2000-2002 on average had little change in the average PNR.

Table 2 provides sample means for failure to rescue (FTR) rates, using the same structure as Table 1. Two important features of the Table merit emphasis. First, we observe that in the pre-regulation years, FTR rates were generally highest in units that had high patient/nurse ratios. Second, we notice that FTR rates generally declined from the pre-regulation period (2000-2002) to the post-regulation period (2005-2006). These declines were observed in each category of hospitals, i.e., in hospitals that initially had high patient/nurse ratios (and which were therefore likely affected by the new regulation) and in 
hospitals that initially had relatively low patient/nurse ratios (and which were not likely affected by the regulation). ${ }^{13}$

Table 3 again follows the format used in Tables 1 and 2-dividing hospitals by PNRs observed in the pre-regulation period - and tracks the rates of decubits ulcers (DU). We notice that in the preregulation period (2000-2002), hospitals with low patient/nurse ratios tended to have relatively low DU rates. Over time, though, these same hospitals are observed to have increases in DU rates (while DU rates remain roughly stable in units that initially had high patient/nurse ratios).

Below we will provide a systematic analysis of the trends shown in these tables. Before doing so, though, we provide summary statistics for some characteristics of the medical/surgical hospital units used in the multivariate analyses. See Table 4. For our regression analysis below, we will often estimate "difference equations" in which we treat 2001-2002 as the "pre-regulation period" and 2005-2006 as the "post-regulation period," so in this Table we present statistics for both of these periods. ${ }^{14}$ We see from this table that hospitals that have high patient/nurse ratios $(\mathrm{PNR}>6)$ tend to be generally smaller than other hospitals, as measured by "discharges." 15 The "case mix" variable, which indicates the severity of illness in each hospital unit, is calculated by taking the average of the relative weighting factor for all diagnosis related groups (DRGs) in the hospital unit during the period analyzed. ${ }^{16}$ The larger the case mix value, the more severe is patient acuity on the unit. Finally, the "skill mix" variable is the percent of productive hours provided by licensed nurses (RNs and LVNs combined) in a hospital that were provided

\footnotetext{
${ }^{13}$ Hospital FTR rates are positively correlated across time, even given changes induced by AB394. For example, we computed a correlation between 2000-2002 rates and 2005-2006 rates of 0.32 (p-value<.0001).

${ }^{14}$ We leave 2000 out of the "pre-regulation period" here because we use that year for forming instruments to use in our instrumental variable analysis.

${ }^{15}$ Discharges are defined as the number of inpatient population who are medically cleared to leave the hospital in the given period analyzed. In our case, this would be the number of discharges averaged between 2001 and 2002 or between 2005 and 2006.

${ }^{16}$ The relative weighting factor for each DRG in a given year is obtained from the Federal Register in the corresponding year that contains this information. The volume and number of the Federal Register differs in each calendar year. This information is available upon request.
} 
by RNs. In general, this percent is quite high for all observed units. Also, this variable is increasing slightly over time; hospitals were not generally substituting away from RNs in response to AB394.

\section{Regression Analysis}

As we have noted, the goal of AB394 was to increase nurse staffing levels, thereby reducing adverse patient health outcomes. As we also noted, much of the evidence pertaining to the hoped-for improvements has come from cross-sectional analysis. With this in mind, we begin by looking at the cross-sectional relationships between our patient outcomes and the patient-to-nurse ratios. In particular we estimate cross-section regressions of the form:

(1) $P S I_{i}=\alpha_{0}+\alpha_{1} P N R_{i}+\alpha_{2} X_{i}+\varepsilon_{i}$,

where $\mathrm{PSI}_{i}$ is a measure of hospital unit $i$ 's patient safety indicator (PSI) rate, averaged over the period under study, $P N R_{i}$ is a measure of the unit patient-to-nurse ratio averaged over the period, and $X_{i}$ is a vector of unit-specific covariates averaged over the period (discharges, RN skill mix, and case mix).

We begin by estimating equation (1) using failure to rescue as the PSI. Results are given in Table 5, for two time periods, the pre-regulation period (2000-2002) and the post-regulation period (20052006). We estimate this regression without and with covariates. In both specifications and in both periods, the PNR is positively correlated with failure to rescue. As in the previous literature using crosssectional data, we observe higher failure to rescue where there is a higher patient/nurse ratio. The relationship is statistically significant, and the estimated effect is small but non-negligible. For example, in the 2000-2002 regression that includes "controls," an increase in the number of patients per nurse by 1 is associated with an increase in the rate of failure to rescue of 0.003 - an increase of approximately $2 \%$, given that average failure to rescue is approximately 0.17 . Of course, as we discuss above, interpretation is problematic, given the potential problems of omitted variables and patient selection.

We next estimate equation (1) using the decubitus ulcer (DU) rate as the PSI, again for the two time periods, 2000-2002 and 2005-2006. Results are in Table 6. The estimated coefficients for the 2000- 
2002 period are as one would expect. Higher patient/nurse ratios are associated with higher DU rates. An increase of 1 in the number of patients per nurse is associated with an increase in the DU rate of 0.0012 (a $5 \%$ increase, given that the average rate is 0.025 ). Surprisingly, the relationship reverses in $2005-2006$. In this time period, relatively low patient/nurse ratios are associated with higher DU rates.

To get an idea of what might be happening with reported DU rates in our data, we return to Table 3. Consider those hospitals that in the 2000-2002 period had the lowest patient loads (fewer than 4 patients per nurse). In 2000, DU rates were very low in these hospitals, but DU rates increased steadily in these same hospitals, so that by 2006 these units had the relatively high DU rates. Notice that this increase in reported DU rates occurred even though those same units continued to have generally low patient/nurse loads (see Table 1) and were steadily improving on our other key PSI—failure to rescue (see Table 3).

A plausible explanation has to do with the nature of reported decubitus ulcers. Over the past several years, there has been considerable attention given to this condition, in hospitals and even in the public press. Part of this attention has been due to legal suits, in which patients with DUs have won substantial awards. In addition, the Centers for Medicare and Medicaid Services (CMS) have been pushing a well-publicized migration to a severity-based payment system, under which payments to hospitals have been reduced for patients that develop DUs. ${ }^{17}$ The consequence is that nurses on well-run units have become increasingly sensitive about diagnosing DU cases present on admission (POA). This is a potentially important issue because previous research indicates that in California in $2003,89 \%$ of DU cases were POA (Houchens, Elixhauser, and Romano, 2008). The point here is that the increasing DU rates reported for the "best hospitals" (i.e., the hospitals that use low patient/nurse rates) might be an indication that medical personnel in these hospitals are especially attentive to diagnosing DU cases POA.

\footnotetext{
${ }^{17}$ These new rules went into effect in October 2008, but attentive health care providers no doubt began to pay closer attention to DU rates during the years leading up to the implementation of this policy.
} 
In principal this should not be a problem since we exclude DU cases that are indicated as POA. But it is difficult to know the level of accuracy of these records. ${ }^{18}$

Given the concerns we have raised in the previous paragraphs, we do not conduct further analysis on DU rates using our data. Instead, we view this case as underscoring previous work cautioning researchers who use DU rates as a PSI (e.g., Houchens et al., 2008, and Polancich, et al., 2006). ${ }^{19}$

We turn now to our primary analysis, which is intended to measure the causal relationship between patient/nurse ratios and our other PSI, failure to rescue. As we have emphasized, cross-sectional analysis is suspect for the purpose of estimating this relationship. Our concern is that the true relationship between patient safety and the PNR is given not by (1), but instead by

$$
P S I_{i}=\alpha_{0}+\alpha_{1} P N R_{i}+\alpha_{2} X_{i}+\alpha_{3} S_{i}+\varepsilon_{i},
$$

which includes an additional (unobserved) set of variables, $S_{i}$. If we estimate (1) rather than (2), the OLS estimate of $\alpha_{1}$ is of course inconsistent if $S_{i}$ and $P N R_{i}$ are correlated, as seems quite plausible. In our case, we can make headway as follows. We first take a "first difference" of equation (2),

$$
\Delta P S I_{i}=\beta_{0}+\beta_{1} \Delta P N R_{i}+\beta_{2} \Delta X_{i}+\left[\beta_{3} \Delta S_{i}+\Delta \varepsilon_{i}\right],
$$

where differences are taken between the 2005-2006 and 2001-2002 time periods. We have no data for $\Delta S_{i}$ (indeed we do not even know what variables appropriately should be included in the vector $S$ ) and if we were to estimate (3), treating the term in brackets as an error term, that error term might well be correlated with $P N R_{i}$, If so, OLS would obviously still give inconsistent estimates of regression parameters.

Given the new regulation, though, we have a reasonable way to proceed. As we have seen in Table 1, hospitals that initially had high levels of PNR generally had substantial decreases in PNR from

\footnotetext{
${ }^{18}$ Polancich, Restrepo, and Prosser's (2006) validation study, which matched AHRQ patient safety indicators with patient medical charts, suggests that the AHRQ methodology substantially over-estimates DU rates. (They point out that many patients who transfer from nursing facility are admitted via an order from an emergency department physician, and are therefore recorded as an emergency department admission.)

19 Also, results reported in Tables 3 and 5 clearly provide reason to be concerned about previous work, based on cross-sectional analysis that attempts to links nurse staffing ratios and DU rates.
} 
the pre-regulation time period to the post-regulation time period. This makes sense. After all, the 2004 regulation mandated that all hospitals maintain the mandated staffing minimum, which meant that some hospitals had to substantially increase staffing levels, while others did not. To capture that idea, we define $D_{i}$ to be the difference between the required nurse staffing level (as implemented in 2004) and hospital $i$ 's staffing level in 2000. Clearly, we expect that the change in the patient/nurse ratio, $\Delta P N R_{i}$, to be correlated with $D_{i}$, and we expect that relationship to be nonlinear, so we use $D_{i}, D_{i}^{2}$, and $D_{i}^{3}$ as instruments. Thus we have a standard two-stage instrumental variables (IV) procedure: The first stage regression has

$$
\Delta P N R_{i}=\theta_{0}+\theta_{1} D_{i}+\theta_{2} D_{i}^{2}+\theta_{3} D_{i}^{3}+\theta_{4} \Delta X_{h}+v_{h} .
$$

Then in the second stage we use the predicted value of $\triangle P N R_{i}$ in estimating regression (3). ${ }^{20}$

Table 7 provides the results. The first two columns show OLS estimates for two specifications based on (3) - one without covariates and one with covariates. Estimates of the key parameter of interest - the association between PNR and failure to rescue - are very close to 0 . Turning to the IV estimates, we note, first of all, that in the first stage the instruments are both individually and jointly highly significant. ${ }^{21}$ As is clear, though, from the second set of columns in Table 7, we find no significant effect of the change in the patient/nurse ratio on failure to rescue. Estimated effects are very small and are imprecisely estimated.

As a check on this key result, we separated our sample into 108 hospitals in Northern California and 186 hospitals in Middle/Southern California, and repeated the analysis given in Table 7. Similarly, we separated the sample into 177 non-profit hospitals and 68 "investor hospitals," and conducted analysis

\footnotetext{
${ }^{20}$ Notice that $\triangle P N R_{i}$ is measured from 2005-2006 to 2001-2002, while the instruments $D_{i}, D_{i}{ }^{2}$, and $D_{i}^{3}$ are formed in 2000. Our reason for using a different year for the instruments is concern about measurement error. As discussed above, our $P N R$ variable is measured with error. Thus if we had formed instruments using the same year as our $\triangle P N R_{i}$ variables, it is possible that the correlation might be due simply to this measurement error. Our strategy then relies on an assumption that measurement error in our $P N R$ measures are not correlated between 2000 (data used to form instruments) and either 2001-2002 or 2005-2006 (data used to form differences in PNR).

${ }^{21}$ Estimates of the coefficients for $D, D^{2}$, and $D^{3}$, and their standard errors (in parentheses) are, respectively, 0.464 (0.074), -0.109 (0.032), and $-0.013(0.010)$. The F statistic for the joint significance of the instruments is 17.0 , so we clearly do not have the problem of "weak instruments" (as discussed, e.g., in Staiger and Stock, 1997).
} 
separately for these samples. The results were similar across these sub-samples; in no cases did we find a statistically significant impact of the change in the patient/nurse ratio on failure to rescue. ${ }^{22}$

In sum, we find no evidence of a causal impact of patient/nurse ratio on failure to rescue. The basic story is seen clearly from Tables 1 and 2. From the pre-regulation period to the post-regulation period, there was apparently an impact of AB394 on nurse staffing levels in some hospitals. Table 1 shows that hospitals which initially had high patient-to-nurse ratios substantially increased nursing levels, bringing them closer to those hospitals that initially had relatively low patient/nurse ratios. However, Table 2 shows that improvements in the failure to rescue rates were similar among all categories of hospitals - those with initially high patient/nurse ratios and those with initially low patient/nurse ratios. Regression results reported in Table 7 confirm these basic observations.

\section{Discussion}

This paper presents an analysis of California's AB394, a law that mandated minimum nurse staffing levels in that State. We examine rates of decubitus ulcers, and conclude that such analysis is not helpful in measuring the impact of the law on patient safety. More helpfully, we examine the impact on failure to rescue rates.

We find persuasive evidence that AB394 did have the intended effect of decreasing patient/nurse ratios in hospitals that previously did not meet mandated standards. However, our analysis suggests that failure to rescue rates did not disproportionately improve in these same hospitals. That is, we find no evidence of a causal impact of the law on patient safety.

There is an important caveat to our analysis. Our empirical results suggest that a mandate reducing patient/nurse ratios, on its own, need not lead to improved patient safety. This is not to say, though, that nurse staffing decisions are unimportant as a component in a hospital's overall strategy for ensuring high patient safety. In particular, it is worth emphasizing that in our data there is a statistically

${ }^{22}$ Tables containing these results are available upon request. 
significant positive cross-sectional relationship between patient/nurse ratios and failure to rescue (as in much of the previous literature). We have noted the difficulties associated with drawing causal inferences on the basis of such results. Nonetheless, apparently those hospitals that are most effective in ensuring patient safety generally find it optimal to employ more nurses per patient. Perhaps there are complementarities between nursing inputs and other (possibly unobserved) inputs and policies that lead to better patient safety. Thus, improved nurse staffing might be crucial in improving patient safety, but only in combination with other elements. It is important that analysts, policy-makers, and healthcare providers sort out these important issues. 


\section{References}

Agency for Healthcare Research and Quality. 2003. AHRQ Quality Indicators: Guide to Patient Safety Indicators (Rep. No. 03-R203 - Version 3.1.) Rockville, MD: AHRQ.

Aiken L.H., Clarke S.P., Sloane D.M., Sochalski J., and Silber J.H. 2002. Hospital Nurse Staffing and Patient Mortality, Nurse Burnout, and Job Dissatisfaction. Journal of the American Medical Association, 288(16): 1987-1993.

Bartel A.P., Phibbs C.S., Beaulieu N., and Stone P.W., 2009. Human Capital and Productivity: The Case of Nursing Teams. Working Paper, Columbia Business School.

Bloom, N. Propper, C., Seiler, S. and Van Reenen, J. 2009. Management Practices in Hospitals. unpublished manuscript, London School of Economics.

Cho S.H., Ketefian S., Barkauskas V.H., and Smith D.G. 2003. The Effects of Nurse Staffing on Adverse Events, Morbidity, Mortality, and Medical Costs. Nursing Research, 52(2): 71-79.

Clarke S.P. 2003. Balancing Staffing and Safety. Nursing Management, 34(6): 44-48.

Clarke S.P. 2005. The Policy Implications of Staffing-Outcomes Research. Journal of Nursing Administration, 35(1): 17-19.

Coffman J.M., Seago J.A., and Spetz, J. 2002. Minimum Nurse-to-Patient Ratios in Acute Care Hospitals in California. Health Affairs, 21(5): 53-64.

Cook, A. 2009. Is There a Nurse in the House? The Effect of Nurse Staffing Increases on Patient Health Outcomes. Chapter 3, unpublished doctoral dissertation, Carnegie Mellon University.

Dobkin C. 2003. Hospital Staffing and Patient Mortality. Working Paper, Department of Economics, University of California, Berkeley. Available at http://people.ucsc.edu/ cdobkin/Papers.

Donaldson N.E. 2005. Impact of CA's Licensed Nurse-Patient Ratios on Unit-Level Nurse Staffing and Patient Outcomes. Policy, Politics, and Nursing Practice, 6(3): 198-210.

Dunton N. and Schumann M.J. 2005. Early Evidence on California Staffing Ratios Should be Interpreted with Caution. Policy, Politics, and Nursing Practice, 6(4):354-357.

Evans W.N. and Kim B. 2006. Patient Outcomes When Hospitals Experience a Surge in Admissions. Journal of Health Economics, 25(2): 365-388.

Gerdtz M.F. 2007. 5-20: A Model of Minimum Nurse-to-Patient Ratios in Victoria, Australia. Journal of Nursing Management, 15: 64-71.

Goodin H.J. 2003. The Nursing Shortage in the United States of America: An Integrative Review of the Literature. Journal of Advanced Nursing, 43(3): 335-350.

Houchens R., Elixhauser A. and Romano, P. 2008. How Often are Potential Patient Safety Events Present on Admission? Joint Commission Journal on Quality and Patient Safety, 34(3): 154-163. 
Institute for Health and Socio-Economic Policy. 2001. AB 394: California and the Demand for Safe and Effective Nurse to Patient Staffing Ratios. Prepared for the California Nurses Association.

Kane, R.L., Shamliyan, T., Mueller, C. Duval, S., and Wilt, T. 2007. Nursing Staffing and Quality of Patient Care. Evidence Report/Technology Assessment No. 151(Prepared by the Minnesota Evidence Based Practice Center under Contract No. 290-02-0009.) AHRQ Publication No. 07E005. Rockville, MD: Agency for Healthcare Research and Quality.

Kohn, L.T., Corrigan, J.M., and Donaldson, M. 1999. To Err is Human: Building a Safer Health System. Washington, DC: National Academy Press.

Lang, T.A., Hodge, M., Olson, V., Romano, P.S., and Kravitz, R.L. 2004. Nurse-Patient Ratios: A Systematic Review on the Effects of Nurse Staffing on Patient, Nurse Employee, and Hospital Outcomes. Journal of Nursing Administration, 34(7-8): 326-337.

Lichtig, L.K., Knauf, R.A., and Milholland, D.K. 1999. Some Impact of Nursing on Acute Care Hospital Outcomes. Journal of Nursing Administration, 29(2): 25-33.

Mark, B.A., Salyer, J., and Wan, T.T. 2003. Professional Nursing Practice: Impact on Organizational and Patient Outcomes. Journal of Nursing Administration, 33: 224-234.

Mark, B.A., Harless, D., McCue, M., and Yihua, X. 2004. A Longitudinal Examination of Hospital Registered Nurse Staffing and Quality of Care. Health Services Research, 39: 279-299.

Matsudaira, J. 2009. The Labor Market Effects of Minimum Staffing Legislation: Direct Tests for Monopsony in High- and Low-Skilled Labor Markets. unpublished manuscript, Cornell University.

McClellan, M. and Staiger, D. 2000. Comparing the Quality of Health Care Providers. In Frontiers in Health Policy Research, vol. 3, pp. 113-36. A. Garber, ed. Cambridge, MA: MIT Press.

Needleman, J., Buerhaus, P.I., Mattke, S., Stewart, M., and Zelvinsky, K. 2001. Nurse Staffing and Patient Outcomes in Hospitals. Final Report of US DHHS Health Resources and Services Administration, Contract No. 230-99-0021.

Needleman, J., Buerhaus, P., Mattke, S., Stewart, M., and Zelevinsky, K. 2002. Nurse Staffing Levels and the Quality of Care in Hospitals. The New England Journal of Medicine, 346(22): 17151722 .

Polancich, S., Restrepo, E., and Prosser, J. 2006. Cautious Use of Administrative Data for Decubitus Ulcer Outcome Reporting. American Journal of medical Quality, 21(4): 262-268.

Propper, C. and Van Reenen, J. 2010. Can Pay Regulation Kill? Panel Data Evidence on the Effect of Labor Markets on Hospital Performance. Journal of Political Economy, 118: 222-273.

Rosdahl, C.B. and Kowalski, M.T. 2007. Textbook of Basic Nursing. Lippincott, Williams, and Wilkins, $9^{\text {th }}$ Edition. 
Seago, J.A. 2002. The California Experiment: Alternatives for Minimum Nurse-to-Patient Ratios. Journal of Nursing Administration, 32(1): 48-58.

Sochalski, J., Konetzka, T., Zhu, J., and Volpp, K. 2008. Will Mandatory Nurse Staffing Ratios Lead to Better Patient Outcomes in Hospitals? Medical Care, 46(6): 606-13.

Spetz, J. 2004. California's Minimum Nurse-to-Patient Ratios: The First Few Months. Journal of Nursing Administration, 34(12): 571-578.

Spetz, J., Chapman S., Herrera, C., Kaiser, J., Seago, J.A., and Dower, C. 2009. Assessing the Impact of California's Nurse Staffing Ratios on Hospitals and Patient Care. California Healthcare Foundation: Issue Brief - February.

Staiger, D. and Stock, J. 1997. Instrumental Variables Regression with Weak Instruments. Econometrica, 65(3): 557-586.

Stone, P.W., Mooney-Kane, C., Larson, E.L., Horan, T., Glance, L.G., Zwanziger, J., Dick, A.W. 2007. Nurse Working Conditions and Patient Safety Outcomes. Medical Care, 45(6): 571-578.

Unruh, L. 2003. Licensed Nurse Staffing and Adverse Events in Hospitals. Medical Care, 41(1): 142152.

United States Department of Health and Human Services. 2005. Pocket Guide to Minority Health Resources. Washington D.C.: United States Department of Health and Human Services - Office of Public Health and Science. 
Table 1. Sample Means of the Patient-to-Nurse Ratio (PNR), 2000-2006

\begin{tabular}{|c|c|c|c|c|c|c|c|c|c|c|}
\hline $\begin{array}{l}\text { Unit } \\
\text { Grouping } \\
\text { in 2000- } \\
2002\end{array}$ & Obs. & 2000 & 2001 & 2002 & 2003 & 2004 & 2005 & 2006 & $\begin{array}{l}\text { Pre- } \\
\text { Regulation } \\
(2000- \\
2002) \\
\end{array}$ & $\begin{array}{l}\text { Post- } \\
\text { Regulation } \\
(2005- \\
2006)\end{array}$ \\
\hline $\mathrm{PNR}>6$ & 53 & $\begin{array}{c}6.64 \\
(0.18)\end{array}$ & $\begin{array}{c}7.17 \\
(0.16)\end{array}$ & $\begin{array}{c}7.36 \\
(0.20)\end{array}$ & $\begin{array}{c}6.55 \\
(0.26)\end{array}$ & $\begin{array}{c}5.42 \\
(0.20)\end{array}$ & $\begin{array}{c}4.80 \\
(0.18)\end{array}$ & $\begin{array}{c}4.62 \\
(0.17)\end{array}$ & $\begin{array}{c}7.06 \\
(0.14)\end{array}$ & $\begin{array}{c}4.71 \\
(0.16)\end{array}$ \\
\hline $6>\mathrm{PNR}>5$ & 94 & $\begin{array}{c}5.41 \\
(0.07)\end{array}$ & $\begin{array}{c}5.53 \\
(0.06)\end{array}$ & $\begin{array}{c}5.36 \\
(0.07)\end{array}$ & $\begin{array}{c}5.16 \\
(0.14)\end{array}$ & $\begin{array}{c}4.68 \\
(0.10)\end{array}$ & $\begin{array}{c}4.39 \\
(0.12)\end{array}$ & $\begin{array}{c}4.15 \\
(0.10)\end{array}$ & $\begin{array}{c}5.43 \\
(0.03)\end{array}$ & $\begin{array}{c}4.27 \\
(0.10)\end{array}$ \\
\hline $5>\mathrm{PNR}>4$ & 96 & $\begin{array}{c}4.52 \\
(0.06)\end{array}$ & $\begin{array}{c}4.61 \\
(0.06)\end{array}$ & $\begin{array}{c}4.58 \\
(0.07)\end{array}$ & $\begin{array}{c}4.45 \\
(0.08)\end{array}$ & $\begin{array}{c}4.25 \\
(0.09)\end{array}$ & $\begin{array}{c}3.97 \\
(0.10)\end{array}$ & $\begin{array}{c}3.83 \\
(0.09)\end{array}$ & $\begin{array}{c}4.57 \\
(0.03)\end{array}$ & $\begin{array}{c}3.90 \\
(0.09)\end{array}$ \\
\hline $4>\mathrm{PNR}$ & 51 & $\begin{array}{c}3.23 \\
(0.10)\end{array}$ & $\begin{array}{c}3.55 \\
(0.12)\end{array}$ & $\begin{array}{c}3.55 \\
(0.09)\end{array}$ & $\begin{array}{c}3.68 \\
(0.11)\end{array}$ & $\begin{array}{c}4.05 \\
(0.26)\end{array}$ & $\begin{array}{c}3.50 \\
(0.12)\end{array}$ & $\begin{array}{c}3.39 \\
(0.14)\end{array}$ & $\begin{array}{c}3.44 \\
(0.07)\end{array}$ & $\begin{array}{c}3.45 \\
(0.12)\end{array}$ \\
\hline $\begin{array}{l}\text { Overall } \\
\text { Means }\end{array}$ & 294 & $\begin{array}{c}4.95 \\
(0.08)\end{array}$ & $\begin{array}{c}5.17 \\
(0.08)\end{array}$ & $\begin{array}{c}5.14 \\
(0.09)\end{array}$ & $\begin{array}{c}4.91 \\
(0.09)\end{array}$ & $\begin{array}{c}4.56 \\
(0.08)\end{array}$ & $\begin{array}{c}4.17 \\
(0.07)\end{array}$ & $\begin{array}{c}3.99 \\
(0.06)\end{array}$ & $\begin{array}{c}5.08 \\
(0.07)\end{array}$ & $\begin{array}{c}4.08 \\
(0.06)\end{array}$ \\
\hline
\end{tabular}


Table 2. Sample Means of Failure to Rescue (FTR) Rates, 2000-2006

\begin{tabular}{|c|c|c|c|c|c|c|c|c|c|c|}
\hline $\begin{array}{l}\text { Unit Grouping } \\
\text { in } 2000-2002\end{array}$ & Obs. & 2000 & 2001 & 2002 & 2003 & 2004 & 2005 & 2006 & $\begin{array}{c}\text { Pre- } \\
\text { Regulation } \\
(2000-2002)\end{array}$ & $\begin{array}{c}\text { Post- } \\
\text { Regulation } \\
(2005-2006) \\
\end{array}$ \\
\hline $\mathrm{PNR}>6$ & 53 & $\begin{array}{c}0.178 \\
(0.007)\end{array}$ & $\begin{array}{c}0.178 \\
(0.010)\end{array}$ & $\begin{array}{c}0.174 \\
(0.007)\end{array}$ & $\begin{array}{c}0.173 \\
(0.008)\end{array}$ & $\begin{array}{c}0.168 \\
(0.008)\end{array}$ & $\begin{array}{c}0.153 \\
(0.010)\end{array}$ & $\begin{array}{c}0.157 \\
(0.009)\end{array}$ & $\begin{array}{c}0.177 \\
(0.006)\end{array}$ & $\begin{array}{c}0.155 \\
(0.008)\end{array}$ \\
\hline $6>\mathrm{PNR}>5$ & 94 & $\begin{array}{c}0.171 \\
(0.005)\end{array}$ & $\begin{array}{c}0.172 \\
(0.005)\end{array}$ & $\begin{array}{c}0.169 \\
(0.005)\end{array}$ & $\begin{array}{c}0.167 \\
(0.005)\end{array}$ & $\begin{array}{c}0.160 \\
(0.004)\end{array}$ & $\begin{array}{c}0.151 \\
(0.004)\end{array}$ & $\begin{array}{c}0.127 \\
(0.007)\end{array}$ & $\begin{array}{c}0.171 \\
(0.003)\end{array}$ & $\begin{array}{c}0.139 \\
(0.004)\end{array}$ \\
\hline $5>\mathrm{PNR}>4$ & 96 & $\begin{array}{c}0.164 \\
(0.005)\end{array}$ & $\begin{array}{c}0.168 \\
(0.005)\end{array}$ & $\begin{array}{c}0.171 \\
(0.005)\end{array}$ & $\begin{array}{c}0.159 \\
(0.004)\end{array}$ & $\begin{array}{c}0.154 \\
(0.005)\end{array}$ & $\begin{array}{c}0.142 \\
(0.004)\end{array}$ & $\begin{array}{c}0.115 \\
(0.007)\end{array}$ & $\begin{array}{c}0.168 \\
(0.004)\end{array}$ & $\begin{array}{c}0.129 \\
(0.004)\end{array}$ \\
\hline $4>\mathrm{PNR}$ & 51 & $\begin{array}{c}0.157 \\
(0.008)\end{array}$ & $\begin{array}{c}0.168 \\
(0.008)\end{array}$ & $\begin{array}{c}0.153 \\
(0.009)\end{array}$ & $\begin{array}{c}0.153 \\
(0.008)\end{array}$ & $\begin{array}{c}0.138 \\
(0.008)\end{array}$ & $\begin{array}{c}0.138 \\
(0.007)\end{array}$ & $\begin{array}{c}0.116 \\
(0.008)\end{array}$ & $\begin{array}{c}0.160 \\
(0.006)\end{array}$ & $\begin{array}{c}0.127 \\
(0.006)\end{array}$ \\
\hline Overall Means & 294 & $\begin{array}{c}0.167 \\
(0.003)\end{array}$ & $\begin{array}{c}0.171 \\
(0.003)\end{array}$ & $\begin{array}{c}0.168 \\
(0.003)\end{array}$ & $\begin{array}{c}0.163 \\
(0.003)\end{array}$ & $\begin{array}{c}0.156 \\
(0.003)\end{array}$ & $\begin{array}{c}0.146 \\
(0.003)\end{array}$ & $\begin{array}{c}0.127 \\
(0.004)\end{array}$ & $\begin{array}{c}0.169 \\
(0.002)\end{array}$ & $\begin{array}{c}0.136 \\
(0.003)\end{array}$ \\
\hline
\end{tabular}


Table 3. Sample Means of Decubitus Ulcer (DU) Rates, 2000-2006

\begin{tabular}{|c|c|c|c|c|c|c|c|c|c|c|}
\hline $\begin{array}{l}\text { Unit } \\
\text { Grouping } \\
\text { in 2000-2002 }\end{array}$ & Obs. & 2000 & 2001 & 2002 & 2003 & 2004 & 2005 & 2006 & $\begin{array}{c}\text { Pre- } \\
\text { Regulation } \\
(2000- \\
2002) \\
\end{array}$ & $\begin{array}{c}\text { Post- } \\
\text { Regulation } \\
(2005- \\
2006) \\
\end{array}$ \\
\hline $\mathrm{PNR}>6$ & 53 & $\begin{array}{c}0.029 \\
(0.002)\end{array}$ & $\begin{array}{c}0.029 \\
(0.002)\end{array}$ & $\begin{array}{c}0.031 \\
(0.003)\end{array}$ & $\begin{array}{c}0.032 \\
(0.002)\end{array}$ & $\begin{array}{c}0.032 \\
(0.002)\end{array}$ & $\begin{array}{c}0.032 \\
(0.002)\end{array}$ & $\begin{array}{c}0.031 \\
(0.002)\end{array}$ & $\begin{array}{c}0.030 \\
(0.002)\end{array}$ & $\begin{array}{c}0.031 \\
(0.002)\end{array}$ \\
\hline $6>\mathrm{PNR}>5$ & 94 & $\begin{array}{c}0.025 \\
(0.001)\end{array}$ & $\begin{array}{c}0.025 \\
(0.001)\end{array}$ & $\begin{array}{c}0.025 \\
(0.001)\end{array}$ & $\begin{array}{c}0.026 \\
(0.001)\end{array}$ & $\begin{array}{c}0.027 \\
(0.001)\end{array}$ & $\begin{array}{c}0.029 \\
(0.001)\end{array}$ & $\begin{array}{c}0.029 \\
(0.001)\end{array}$ & $\begin{array}{c}0.025 \\
(0.001)\end{array}$ & $\begin{array}{c}0.029 \\
(0.001)\end{array}$ \\
\hline $5>\mathrm{PNR}>4$ & 96 & $\begin{array}{c}0.024 \\
(0.001)\end{array}$ & $\begin{array}{c}0.025 \\
(0.001)\end{array}$ & $\begin{array}{c}0.025 \\
(0.001)\end{array}$ & $\begin{array}{c}0.027 \\
(0.001)\end{array}$ & $\begin{array}{c}0.028 \\
(0.001)\end{array}$ & $\begin{array}{c}0.028 \\
(0.001)\end{array}$ & $\begin{array}{c}0.027 \\
(0.001)\end{array}$ & $\begin{array}{c}0.025 \\
(0.001)\end{array}$ & $\begin{array}{c}0.028 \\
(0.001)\end{array}$ \\
\hline $4>\mathrm{PNR}$ & 51 & $\begin{array}{c}0.022 \\
(0.001)\end{array}$ & $\begin{array}{c}0.024 \\
(0.002)\end{array}$ & $\begin{array}{c}0.026 \\
(0.002)\end{array}$ & $\begin{array}{c}0.027 \\
(0.002)\end{array}$ & $\begin{array}{c}0.032 \\
(0.002)\end{array}$ & $\begin{array}{c}0.030 \\
(0.002)\end{array}$ & $\begin{array}{c}0.032 \\
(0.002)\end{array}$ & $\begin{array}{c}0.024 \\
(0.001)\end{array}$ & $\begin{array}{c}0.031 \\
(0.002)\end{array}$ \\
\hline $\begin{array}{l}\text { Overall } \\
\text { Means }\end{array}$ & 294 & $\begin{array}{c}0.025 \\
(0.001)\end{array}$ & $\begin{array}{c}0.025 \\
(0.001)\end{array}$ & $\begin{array}{c}0.026 \\
(0.001)\end{array}$ & $\begin{array}{c}0.027 \\
(0.001)\end{array}$ & $\begin{array}{c}0.029 \\
(0.001)\end{array}$ & $\begin{array}{c}0.029 \\
(0.001)\end{array}$ & $\begin{array}{c}0.029 \\
(0.001)\end{array}$ & $\begin{array}{c}0.026 \\
(0.001)\end{array}$ & $\begin{array}{c}0.029 \\
(0.001)\end{array}$ \\
\hline
\end{tabular}


Table 4. Sample Means of Unit Characteristics in 2001-2002 and 2005-2006

\begin{tabular}{lcccccc}
\hline $\begin{array}{l}\text { Unit Grouping } \\
\text { in 2001-2002 }\end{array}$ & \multicolumn{2}{c}{ Discharges (in 1,000s) } & \multicolumn{2}{c}{ Case Mix } & \multicolumn{2}{c}{ Skill Mix (\% RN) } \\
\hline 2001-2002 & 2005-2006 & $2001-2002$ & $2005-2006$ & $2001-2002$ & 2005-2006 \\
\hline PNR $>6$ & 4.2 & 4.5 & 1.26 & 1.15 & 86.2 & 85.9 \\
$6>$ PNR $>5$ & 5.8 & 6.5 & 1.30 & 1.21 & 86.9 & 87.4 \\
$5>$ PNR $>4$ & 6.5 & 7.2 & 1.31 & 1.22 & 84.2 & 87.1 \\
$4>$ PNR & 6.2 & 6.3 & 1.31 & 1.24 & 82.5 & 86.0 \\
\hline
\end{tabular}


Table 5. The Relationship Between the Patient/Nurse Ratio and Failure to Rescue (FTR): Cross-Sectional Analysis

\begin{tabular}{|c|c|c|c|c|}
\hline & \multicolumn{2}{|c|}{$2000-2002$} & \multicolumn{2}{|c|}{$2005-2006$} \\
\hline PNR & $\begin{array}{l}0.0037 * * \\
(0.0017)\end{array}$ & $\begin{array}{l}0.0030^{*} \\
(0.0017)\end{array}$ & $\begin{array}{c}0.0068 * * * \\
(0.0021)\end{array}$ & $\begin{array}{l}0.0037^{*} \\
(0.0021)\end{array}$ \\
\hline Discharges & -- & $\begin{array}{l}-0.0001 \\
(0.0033)\end{array}$ & -- & $\begin{array}{l}-0.0050 \\
(0.0000)\end{array}$ \\
\hline Case Mix & -- & $\begin{array}{c}-0.0251 * * \\
(0.0104)\end{array}$ & -- & $\begin{array}{c}-0.0464 * * * \\
(0.0136)\end{array}$ \\
\hline Skill Mix & -- & $\begin{array}{l}-0.0161 \\
(0.0181)\end{array}$ & -- & $\begin{array}{l}-0.0115 \\
(0.0206)\end{array}$ \\
\hline $\begin{array}{l}\mathrm{R}^{2} \\
\text { observations }\end{array}$ & $\begin{array}{l}0.02 \\
294\end{array}$ & $\begin{array}{l}0.04 \\
294\end{array}$ & $\begin{array}{l}0.04 \\
294\end{array}$ & $\begin{array}{l}0.11 \\
294\end{array}$ \\
\hline
\end{tabular}


Table 6. The Relationship Between the Patient/Nurse Ratio and the Decubitus Ulcer (DU) Rate: Cross-Sectional Analysis

\begin{tabular}{lcccc}
\hline \multicolumn{2}{c}{$2000-2002$} & \multicolumn{2}{c}{$2005-2006$} \\
\hline PNR & $0.0012^{* *}$ & $0.0012^{* *}$ & $-0.0025^{* * *}$ & $-0.0027^{* * *}$ \\
& $(0.0006)$ & $(0.0006)$ & $(0.0007)$ & $(0.0008)$ \\
Discharges & -- & -0.0003 & -- & -0.0001 \\
& & $(0.0011)$ & & $(0.0012)$ \\
Case Mix & -- & 0.0011 & -- & -0.0070 \\
& & $(0.0035)$ & & $(0.0049)$ \\
Skill Mix & -- & -0.0024 & -- & 0.0036 \\
& & $(0.0061)$ & & $(0.0074)$ \\
$\mathrm{R}^{2}$ & & & & \\
observations & 0.02 & 0.02 & 0.04 & 0.05 \\
\hline
\end{tabular}

Dependent variable is ... Significance: ${ }^{*} \mathrm{p}<0.10,{ }^{* *} \mathrm{p}<0.05$, and ${ }^{* * *} \mathrm{p}<0.01$, using one-sided tests. 
Table 7. The Relationship Between the Patient/Nurse Ratio and Failure to Rescue Rates: First Difference and IV Analysis

\begin{tabular}{lcccc}
\hline \multicolumn{3}{c}{ OLS } & \multicolumn{2}{c}{ IV } \\
\hline & & & & \\
& -0.0010 & -0.0009 & -0.0014 & -0.0006 \\
& $(0.0023)$ & $(0.0021)$ & $(0.0059)$ & $(0.0052)$ \\
$\Delta$ Discharges & -- & -0.0032 & -- & -0.0034 \\
& & $(0.0104)$ & & $(0.0105)$ \\
$\Delta[$ Case Mix $]$ & -- & $-0.0440^{*}$ & -- & $-0.0439^{*}$ \\
& & $(0.0252)$ & & $(0.0247)$ \\
$\Delta[$ Skill Mix $]$ & -- & -0.0438 & -- & -0.0439 \\
& & $(0.0285)$ & & $(0.0284)$ \\
$\mathrm{R}^{2}$ & & & & \\
observations & 0.00 & 0.02 & 0.00 & 0.02 \\
\hline
\end{tabular}

Significance: ${ }^{*} \mathrm{p}<0.10,{ }^{* *} \mathrm{p}<0.05$, and ${ }^{* * *} \mathrm{p}<0.01$, using one-sided tests. 


\section{Appendix A}

OSHPD inpatient discharge data does not possess information identifying the hospital unit from which the individual was discharged. We found only one documented attempt to create such units from available OSHPD data (Institute for Health and Socio-Economic Policy, 2001). In this study, the authors use a RN expert panel to answer survey questions, including a request to assign DRGs (diagnosis related groups) to one of seven hospital-level-units (intensive care unit, burn care, definitive observation, medical/surgical, pediatrics, psychiatrics, and obstetrics). This methodology seems to present a sound, reputable approach to grouping patients into specific hospital units. Thus, we use it as the basis for defining the general medical/surgical hospital units we analyze in this study. Below, we present the DRGs that make up general medical/surgical units.

\section{General Medical/Surgical Units}

DRGs: 4-6, 8, 9, 11-14, 16-21, 24, 25, 27-29, 31, 32, 34-40, 42-47, 50, 51, 53, 55-57, 59, $61,63-69,71-73,76,77,79,80,82,85,86,88-90,92,93,95,97,99-109,113,114,119$, $120,128,130,131,133-135,141,142,144-155,157-162,164-183,185,187-189,191-$ 208, 210, 211, 213, 216-219, 221-251, 253, 254, 256-278, 280, 281, 283-297, 299-301, 303, 305-313, 315-321, 323-326, 328, 329, 331, 332, 334-339, 341, 342, 344-369, 392, 394, 395, 397-399, 401-404, 406-416, 418-421, 423, 424, 434-437, 439-445, 447, 449, 450, 452-455, 460-469, 471, 473, 476-479, 482, 483, 488-490, 492-494, 496-503, 510, $511,519,520,522,523,525-534,540$, and 543.

\section{References}

Institute for Health and Socio-Economic Policy. 2001. AB 394: California and the Demand for Safe and Effective Nurse to Patient Staffing Ratios. Prepared for the California Nurses Association. 


\section{Appendix B}

One of the most difficult decisions to make when analyzing how nurse staffing affects patient health outcomes is determining which outcomes are most appropriate to use. Ideally, the quality indicators should represent patient outcomes that may be influenced by nurse staffing interventions. Clarke (2003), Naylor (2007), and Needleman, Kurtzman, and Kizer (2007) all provide very informative discussions regarding what characteristics are relevant when attempting to create indicators that connect nurse staffing with patient care. Yet, there is no current consensus or definitive support of data to show which patient outcomes are considered suitable (Hodge, et al., 2004; and Lankshear, Sheldon, and Maynard, 2005), and thus, the literature provides numerous possibilities. The most common methodologies for determining appropriate quality indicators are the following: using an expert panel (usually comprised of nurses) to identify outcomes; and reviewing previous literature to determine which studies provided indicators potentially sensitive to nurse staffing (Lichtig, Knauf, and Milholland, 1999; Kravitz and Sauve, 2002; and Needleman, et al., 2002).

We have read a considerable amount of the literature to evaluate which quality indicators are justifiable for a study that analyzes how changes in nurse staffing affect quality of patient care. Of these articles, only one (Evans and Kim, 2006) actually explains the justification for using the outcomes that they study. Some researchers just take indicators that "seem appropriate." Others use the literature as a guide when choosing outcomes. The strongest justification is to reference outcomes that have been advocated by organizations who conduct quality assurance research on potential nurse-related patient health outcomes. These groups include the American Nurses Association (ANA), the California Nurses Outcome Coalition (CalNOC), the National Quality Forum (NQF), and the Agency for Healthcare Research and Quality (AHRQ). The three "nurse-affected" PSIs we analyze have all been studied and advocated by these groups (AHRQ, 2003; and Naylor, 2007).

The three AHRQ patient safety indicators (PSIs) that we use for this study indicate the probability of problems suffered by patients due to exposure to the healthcare system, and that have a high 
probability of prevention by changes at the provider level (AHRQ, 2003). These problems are referred to as complications or adverse events. These indicators, initially entitled HCUP QIs (Healthcare Cost and Utilization Project Quality Indicators), were created in the mid-1990s in response to the availability of detailed hospital discharge data and hospital firms who desired quality measures that could be analyzed using routine hospital administrative data. Since the creation of the HCUP QIs, the understanding and study of quality indicators has increased significantly. Methods that include risk-adjustment by age, gender, DRG, and co-morbidity have become more prevalent, as have the development of additional indicators. In response to such advances, AHRQ funded the UCSF-Stanford EPC to enhance and continue to develop the original quality indicators. The current AHRQ PSIs were created through a fourstep process that consisted of a literature review, sub-setting the literature review results, face validity testing by clinician panels, and finally empirical testing. Even with the rigorous method by which the AHRQ PSIs were created, there still remain limitations to these outcomes. These include the following: 1) concerns about clinical accuracy of discharge-based diagnosis coding (due to measurement error, selection issues, and sensitivity/specificity problems); and 2) concerns that administrative data may be limited in distinguishing adverse events in which error did not occur from actual medical errors (due to clinical condition code similarities, lack of event timing data, and limited risk adjustment information).

We used AHRQ software to create the two PSIs we employ from OSHPD administrative inpatient discharge data. In order to calculate risk-adjusted PSI rates, the AHRQ software requires information on age, gender, DRGs, and co-morbidities. However, we are using public-use data, and certain information has been "masked" to protect patient confidentiality. Because of this "masked" data, we are only able to use $82 \%$ of the inpatient discharges. Nevertheless, we have determined the information that remains is still representative of the California inpatient discharge population, and thus, our results should not be affected. 


\section{References}

Agency for Healthcare Research and Quality. 2003. AHRQ Quality Indicators: Guide to Patient Safety Indicators (Rep. No. 03-R203 - Version 3.1.) Rockville, MD: AHRQ.

Clarke S.P. 2005. The Policy Implications of Staffing-Outcomes Research. Journal of Nursing Administration, 35(1): 17-19.

Evans W.N. and Kim B. 2006. Patient Outcomes When Hospitals Experience a Surge in Admissions. Journal of Health Economics, 25(2): 365-388.

Hodge M., Romano P.S., Harvey D., Damuels S.J., Olson V.A., Sauve M., and Kravitz R.L. 2004. Licensed Caregiver Characteristics and Staffing in California Acute Care Hospital Units. Journal of Nursing Administration, 34(3): 125-133.

Kravitz, R.L. and Sauve, M.J. 2002. Hospital Nursing Staff Ratios and Quality of Care: Final Report on Evidence, Administrative Data, and Expert Panel Process, and a Hospital Staffing Survey. UC Davis. Prepared for California Department of Health Services.

Lankshear, A.J., Sheldon, T.A., and Maynard, A. 2005. Nurse Staffing and Healthcare Outcomes: A Systematic Review of the International Research Evidence. ANS Advances in Nursing Science, 28: 163-174.

Lichtig, L.K., Knauf, R.A., and Milholland, D.K. 1999. Some Impact of Nursing on Acute Care Hospital Outcomes. Journal of Nursing Administration, 29(2): 25-33.

Naylor, M.D. 2007. Advancing the Science in the Measurement of Health Care Quality Influenced by Nurses. Medical Care Review and Research, 64(2): 144S-169S.

Needleman, J., Buerhaus, P., Mattke, S., Stewart, M., and Zelevinsky, K. 2002. Nurse Staffing Levels and the Quality of Care in Hospitals. The New England Journal of Medicine, 346(22): 17151722 .

Needleman, J., Kurtzman, E.T., and Kizer, K.W. 2007. Performance Measurement of Nursing Care: State of the Science and the Current Consensus. Medical Care Research and Review, 64(2): 10S$43 \mathrm{~S}$. 